\title{
A Mental Health Survey of Different Ethnic and Occupational Groups in Xinjiang, China
}

\author{
Ailing Fu ${ }^{1,+}$, Bo Liu ${ }^{1,2,+}$, Yu Jiang ${ }^{1}$, Junling Zhao ${ }^{1}$, Guanghui Zhang ${ }^{1}$ and Jiwen Liu ${ }^{1, *}$ \\ 1 Department of Occupational Health and Environmental Health, College of Public Health, Xinjiang Medical \\ University, Urumqi 830011, China; 13639949635@163.com (A.F.); Li591552613@163.com (B.L.); \\ jiangyu@stu.xjmu.edu.cn (Y.J.); zhj18899@sina.com (J.Z.); m13199848552@163.com (G.Z.) \\ 2 The First Affiliated Hospital of Xinjiang Medical University, Urumqi 830011, China \\ * Correspondence: PHDTG2015@163.com; Tel.: +86-991-436-5004; Fax: +86-21-6408-5875 \\ + These authors contributed equally to this work.
}

Academic Editor: Carla Sabariego

Received: 2 September 2016; Accepted: 29 December 2016; Published: 5 January 2017

\begin{abstract}
Poor mental health has become a serious social and public health-care burden. This cross-sectional study used multistage stratified cluster random sampling to gather mental health information from 11,891 adults (18-60 years) employed in various occupations categorized according to the Chinese Standard Occupational Classification. Mental health was measured by the General Health Questionnaire, and participants exceeding the cut-off score were defined as having poor mental health. The overall prevalence of poor mental health was $23.8 \%$. The prevalence of poor mental health was significantly higher in the Han ethnic group than Kazak ethnic group and in health-care workers, teachers, and civil servants compared to manual workers. Females (odds ratios $(\mathrm{OR})=1.139,95 \%$ confidence intervals $(\mathrm{CI}): 1.012-3.198)$ and knowledge workers (1.697, 1.097-2.962) were risk factors for poor mental health, while Kazak ethnicity $(0.465,0.466-0.937)$, other minority status (non-Han) $(0.806,0.205-0.987)$, and working $\geq 15$ years in the same occupation $(0.832,0.532-0.932)$ were protective $(p<0.05)$. We concluded that the general level of mental health in Xinjiang, China, is higher in the Kazak ethnic group than the Han ethnic group. The prevalence of poor mental health is higher among knowledge workers than in manual workers due to high incidences of poor mental health in civil servants, health-care workers, and teachers.
\end{abstract}

Keywords: ethnicity; occupation; poor mental health

\section{Introduction}

The World Health Organization (WHO) defines health as a status of well-being conferred by physiological, psychological, and social adaptation [1]. Thus, health is the unity of physiological and mental health. Mental health can be considered the health of an individual within a society, and in order for that society to function, good mental health among the population is a prerequisite [2]. Poor mental health has become a serious global social problem [3]. In fact, mental health (including substance abuse) accounts for as much as one fifth of the global disease burden [4,5]. Mental disorders can damage physical health and are more prevalent among specific occupational groups, reducing productivity and increasing unemployment and associated financial hardship [6].

Many studies have found that there is an association between mental health and certain occupations as well as gender, marital status, life style, and working conditions. Indeed, it has been shown that poor mental health among females is related to being divorced or widowed $[7,8]$. In regards to lifestyles, it is well established that in both developing and developed countries, drinking is harmful to physical and mental health [9]. Additionally, anxiety, depression, and other mental health problems are frequently related to heavy alcohol use [10,11]. Mario [12] published a report indicating 
that cigarette consumption was related to a poorer quality of life as well as mental health, and it has been documented that the physical and mental health of non-smokers is better than smokers [13].

In many developed countries, mental health has been found to be associated with socioeconomic status and ethnicity [14-16]. For example, British of African and/or Caribbean descent are more likely to suffer mental health problems compared to their white British counterparts [17]. Another study found that the Dutch tend to have better mental health than other ethnic groups, which can be partially explained by less stressful working conditions as well as religious beliefs $[18,19]$, which have been shown to have important implications for the promotion of public mental health [18]. Previous studies have also shown that harsh psychosocial working conditions associated with certain occupational groups can lead to a variety of diseases [19] including mental health disorders [20,21] and cardiovascular disease [22]. Specifically, Hämmig [23] postulated that knowledge workers were more likely to have mental health problems compared to manual workers due to the severe psychosocial nature of their jobs. Other studies found work-related stress influenced the mental health of certain occupations, and that high levels of occupational stress were detrimental to the mental health of workers in those occupations [24,25]. Finally, compared to the general population, teachers [26], healthcare workers (especially nurses and physicians) [27,28], and civil servants [23,24] experienced higher occupational stress and worse psychosocial working conditions because of their job role and types of occupation [19].

Compared to the general population, certain occupational groups exhibit greater incidences of poor mental health [29]. While several studies, both domestic and foreign, have examined mental health problems among different occupational groups, most have focused on ethnic majorities [30-32] or a limited number of occupational types, such as healthcare workers, teachers, soldiers, students, pilots, and athletes [33-39]. Moreover, there is an increasing awareness of mental health problems, such as depression and anxiety, among certain occupational groups in China [40], but there has been no comprehensive study of poor mental health prevalence across occupational categories and ethnicity, even though ethnic groups may be a critical determinant of social and occupational status. The current study aimed to assess the overall level of mental health among different ethnic and occupational groups in Xinjiang province and to identify risk factors for poor mental health status.

\section{Methods}

\subsection{Study Site and Population}

We conducted this cross-sectional study using multistage stratified cluster random sampling from April to November 2015 in Xinjiang province, located in the northwest frontier of China and inhabited by 49 ethnic groups, such as Han, Kazak, and Uighur. In the study, a multistage stratified cluster sampling method was used to extract samples as follows. According to different geographical and economic conditions, the 14 prefectures and cities in Xinjiang were divided into four layers: prefecture-level cities; eastern Xinjiang, southern Xinjiang, and northern Xinjiang. In each layer, we took institutions as sampling frames and randomly selected 10-16 institutions from each region, respectively (there were about 250 people per institution). If the institution was picked, on-the-job staff were automatically entered into the sample size.

The initial number of participants selected was 13,010. After rejecting incomplete and incorrectly completed questionnaires, 11,891 working adults aged 18-60 years were included (Table 1), for an effective valid questionnaire response rate of $91.40 \%$. All participants signed the consent form voluntarily.

According to the Chinese Standard Occupational Classification, teachers, medical workers, and civil servants are classified as knowledge workers, while workers, soldiers, and others are classified as manual workers. The study was approved by the ethics committee of Xinjiang Medical University. 
Table 1. Regional distribution of the sample.

\begin{tabular}{|c|c|c|c|c|c|}
\hline \multirow{2}{*}{ Survey Region } & \multicolumn{2}{|c|}{ Survey Sample Size } & \multicolumn{2}{|c|}{ Effective Sample Size } & \multirow{2}{*}{$\begin{array}{c}\begin{array}{c}\text { Effective } \\
\text { Response Rate }\end{array} \\
(\%)\end{array}$} \\
\hline & $N$ (Persons) & Proportion (\%) & $N$ (Persons) & Proportion $(\%)$ & \\
\hline $\begin{array}{c}\text { Urumqi } \\
\text { Municipality }\end{array}$ & 2183 & 16.78 & 2152 & 18.10 & 98.58 \\
\hline Ili Kazak Autonomous Prefecture & 2959 & 22.74 & 2366 & 19.90 & 79.96 \\
\hline Bayingolin Mongol Autonomous Prefecture & 1508 & 11.59 & 1439 & 12.10 & 95.42 \\
\hline Hami region & 1172 & 9.01 & 1072 & 9.02 & 91.47 \\
\hline Changji Hui Autonomous Prefecture & 1009 & 7.76 & 948 & 7.97 & 93.95 \\
\hline Karamay City & 791 & 6.08 & 711 & 5.98 & 89.89 \\
\hline Turpan region & 1182 & 9.09 & 1092 & 9.18 & 92.39 \\
\hline Kashgar region & 2206 & 16.96 & 2111 & 17.75 & 95.69 \\
\hline Total & 13,010 & 100 & 11,891 & 100 & 91.40 \\
\hline
\end{tabular}

\subsection{The Instrument}

This study used a structured questionnaire to collect basic social and demographic information, including sex, age, occupation, marital status, smoking (YES: daily or occasionally, NO: never or rarely), and drinking (YES: daily or more than $500 \mathrm{~mL}$ a week, NO: never or rarely). Mental health was screened using the General Health Questionnaire (GHQ), a self-reported instrument developed by David Goldberg in 1972 [41], now widely applied for screening mental health and psychiatric disorders [42], and whose reliability has been previously validated [43]. The study applied the GHQ-20 (Chinese version of GHQ-20 [43]), which is a supplementary questionnaire of GHQ-12 with better sensitivity [31]. The GHQ-20 was used to assess subjective well-being; it also identifies minor psychiatric disorders, and its excellent reliability and validity in doing so have been shown in many studies [44-46]. The GHQ-20 contains three scales and a total of 20 items. Items 1-9 are sub-scores of self-esteem, 10-15 are related to depression, and 16-20 deal with anxiety [43]. All 20 items are scored 0-0-1-1 (0 points for either of the first two options and 1 point for either of the latter two). The total score for mental health is the combined sub-scores of anxiety, depression, and self-esteem. The higher the total score, the lower the general mental health level. A total score of 4 or more points is considered high-risk, scores of 2-3 points are considered middle-risk, and 1 point or below is considered low-risk. In addition, participants were also classified as high-risk if any supplementary item was answered "poor", "yes", or "often", regardless of total score [43]. In our study, the people at high-risk were considered as having poor mental health, while those at middle-risk and low-risk were considered as not having poor mental health.

\subsection{Validity and Reliability}

This study was conducted with strict quality control at every step. The mental health questionnaire used is considered the international general standard, a preliminary investigation was implemented before the formal investigation. The preliminary investigation was aimed at the occupational population of a university in Xinjiang, whereby 200 people were randomly selected, including teachers, officers, support workers, and others within the occupational population. We adopted a cross-sectional study method in which a questionnaire survey was conducted using GHQ-20. Participants were asked to complete the questionnaire independently and anonymously within $20 \mathrm{~min}$ after which all questionnaires were reviewed and encoded by specialized investigators using EpiData version 3.1 (The EpiData Association, Odense, Denmark) to establish a database. All investigators were qualified postgraduates studying at the Public Health Department of Xinjiang Medical University. In addition, $20 \%$ of entries were randomly compared against the original questionnaire to check the accuracy of the final database. The problems were then summarized for statistical analysis to analyze the reliability of the GHQ-20 using SPSS for Windows v. 17.0 (SPSS Inc., Chicago, IL, USA). In this study, we adopted the Delphi Consensus Method, whereby 18 experts in the field were interviewed using the Chinese and English version of GHQ-20 and these results were combined with the survey results in order to validate the content validity and reliability of the questionnaire. In our study, the content validity was 
deemed acceptable, as the Cronbach's alpha was 0.862 and the split-half reliability was 0.751 . All of the above quality control methods were applied to the formal investigation.

\subsection{Statistical Analysis}

All data was analyzed using SPSS for Windows v. 17.0 (SPSS Inc., Chicago, IL, USA). Continuous variables, such as anxiety, depression, self-esteem, and total GHQ-20 scores were expressed as $\bar{x} \pm s$. Categorical variables or rank variables were expressed as $n(\%)$. Continuous variables were compared among groups by independent sample $t$-tests or one-way ANOVA with Student-Newman-Keuls and least significant difference tests for pair-wise comparisons. Categorical variables were compared among groups by the chi-square test, and if there were statistically significant differences among the groups, the partition of the chi-square method was used for pair-wise comparison. The significant level was adjusted for multiple testing using the Bonferroni correction, the $p$-value for statistical significance is therefore $p=0.003(0.05 / 17)$.

Binary logistic regression analysis was used to analyze the association between factors and poor mental health, those factors with $p$-value $<0.25$ in the chi-square test were chosen to explore explanatory factors independently associated with poor mental health by backward stepwise (Wald) logistic regression analysis, odds ratios (OR) and 95\% confidence intervals (95\% CI) were used to express the strength of factors influencing mental health. The measure of predictive power for the regression model was the Wald test, and the Hosmer-Lemeshow test was applied to measure goodness of fit. The significance level in the logistic regression was set at 0.05 . All tests were two-tailed.

\section{Results}

\subsection{Regional Distribution of the Sample}

Table 1 shows that regional sampling distribution of the 13,010 participants and the effective response rates for each region $(91.40 \%$ overall).

\subsection{The Prevalence of Poor Mental Health for Demographic and Occupational Sub-Groups}

Table 2 presents the prevalence of poor mental health from the GHQ-20 for all valid responses ( $n=11,891)$; the overall prevalence of poor mental health was $23.8 \%$. We found there were statistically significant differences between sexes and among ethnicities, occupations, working year sub-groups, and marital status sub-groups $(p<0.003)$ by using chi-square test. The prevalence of poor mental health was higher in females $(26.4 \%)$ than males $(21.5 \%)(p<0.003)$ and was highest in the Han ethnic group $(25.7 \%)$ and lower in the Uyghur ethnic group $(21.5 \%)(p<0.003)$. The prevalence of poor mental health was higher for teachers $(29.1 \%)$, health-care workers $(28.7 \%)$, and civil servants $(22.2 \%)$ compared to manual workers $(p<0.003)$, and was highest for those working less than five years at any occupation $(47.4 \%)(p<0.003)$. Those who were divorced or widowed had the highest prevalence of poor mental health $(42.5 \%)(p<0.003)$. Thus, shorter working years, divorced or widowed marital status, and employment in a knowledge occupation were associated with a higher prevalence of poor mental health according to the GHQ-20.

Table 2. The prevalence of poor mental health among sub-groups $(n=11,891)$.

\begin{tabular}{|c|c|c|c|c|c|}
\hline & \multirow{3}{*}{ Index } & \multicolumn{2}{|c|}{ Poor Mental Health } & \multirow{3}{*}{$x^{2}$} & \multirow{3}{*}{$p$-Value } \\
\hline & & YES & NO & & \\
\hline & & $n(\%)$ & $n(\%)$ & & \\
\hline \multirow{2}{*}{ Sex } & Male & $1368(21.5)$ & $4994(78.5)$ & \multirow{2}{*}{39.240} & \multirow{2}{*}{$<0.001$} \\
\hline & Female & $1460(26.4)$ & 4069 (73.6) & & \\
\hline \multirow{4}{*}{ Ethnicity } & Han & $1754(25.7)$ & $5251(74.3)$ & \multirow{4}{*}{17.029} & \multirow{4}{*}{0.001} \\
\hline & Uyghur & $710^{\mathrm{a}}(21.5)$ & $2593(78.5)$ & & \\
\hline & Kazak & $76(21.2)$ & $283(78.8)$ & & \\
\hline & Other minority & $288(23.5)$ & $936(76.5)$ & & \\
\hline
\end{tabular}


Table 2. Cont.

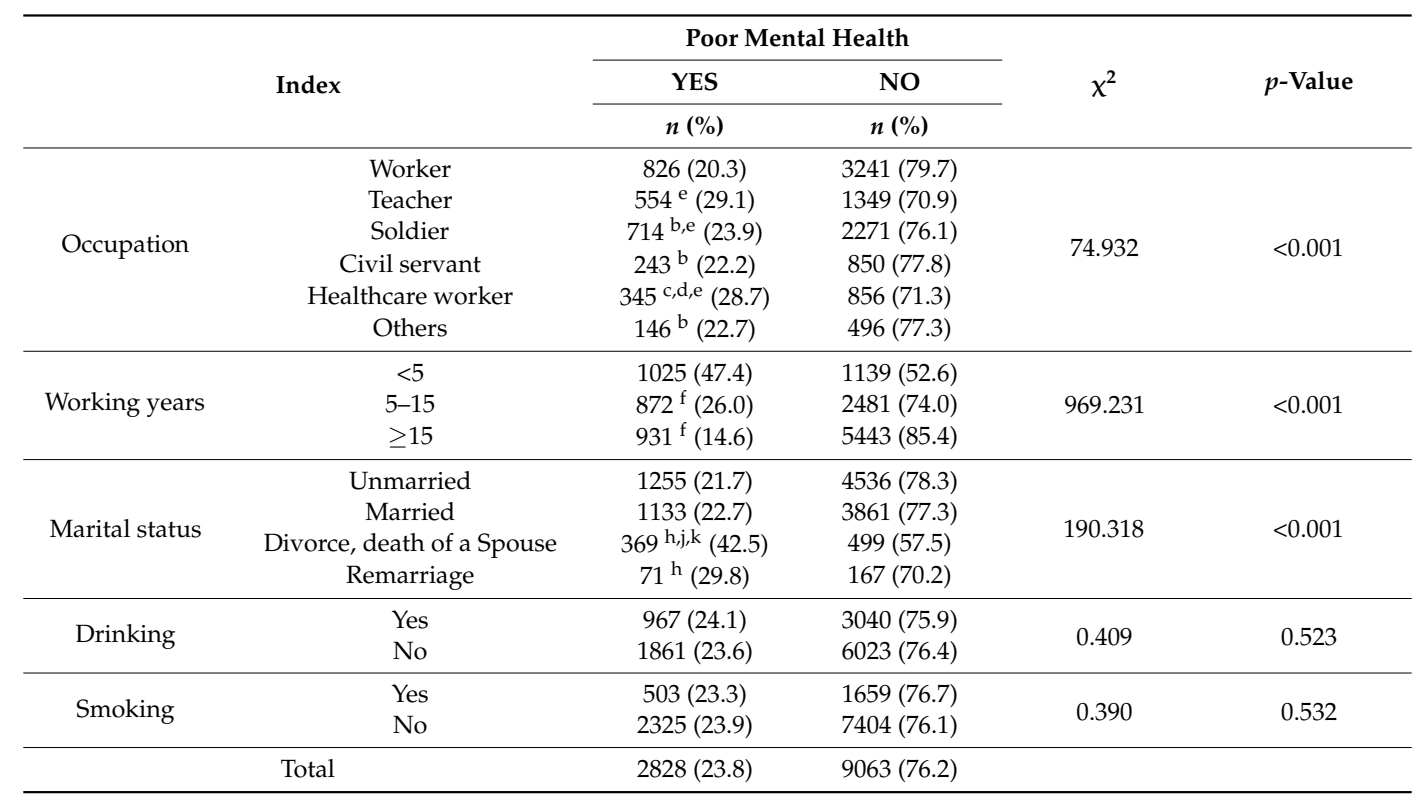

Partition of the chi-square method results: ${ }^{\mathrm{a}} p<0.003$ compared to Han ethnicity; ${ }^{\mathrm{b}} p<0.003$ compared to teachers; ${ }^{\mathrm{c}} p<0.003$ compared to soldiers; ${ }^{\mathrm{d}} p<0.003$ compared to civil servants; ${ }^{\text {e }} p<0.003$ compared to workers; ${ }^{\mathrm{f}} p<0.003$ compared to length of service $<5$ years; ${ }^{\mathrm{h}} p<0.003$ compared to unmarried people; ${ }^{\mathrm{j}} p<0.003$ compared to married people; and ${ }^{\mathrm{k}} p<0.003$ compared to those who were remarried.

\subsection{Comparison of GHQ-20 Total and Subscale Scores among Demographic and Occupational Sub-Groups}

Table 3 displays all statistically significant differences in GHQ-20 total scores as well as self-esteem, depression, and anxiety sub-scores between sexes and smoking status groups, and among occupations and marital status groups $(p<0.003)$. Additionally, results indicated that the self-esteem, depression, and anxiety sub-scores were statistically different among the drinking group $(p<0.003)$. Total scores and all three subscale scores were higher in females than males, in the Han ethnic group compared to Uighur and Kazak ethnic groups, and knowledge workers compared to manual workers $(p<0.003)$. The divorced or widowed groups had higher total scores and lower self-esteem compared to the married and unmarried groups $(p<0.003)$. Smokers had higher self-esteem scores but lower depression, anxiety, and total scores than non-smokers, while drinkers exhibited higher anxiety scores and total scores than non-drinkers but lower depression and self-esteem scores $(p<0.003)$.

Table 3. The General Health Questionnaire (GHQ)-20 scale and subscales score comparison of occupational group with different demographic characteristics.

\begin{tabular}{|c|c|c|c|c|c|}
\hline & $n$ & Self-Esteem & Anxiety & Depression & Total Score \\
\hline \multicolumn{6}{|l|}{ Sex } \\
\hline Male & 6362 & $5.96 \pm 1.42$ & $0.66 \pm 0.42$ & $1.43 \pm 1.13$ & $4.07 \pm 2.69$ \\
\hline Female & 5529 & $7.02 \pm 1.57$ & $0.87 \pm 0.62$ & $1.52 \pm 1.22$ & $5.28 \pm 3.35$ \\
\hline$t$ & & 38.45 & 21.34 & 4.16 & 21.51 \\
\hline$p$-value & & $<0.001$ & $<0.001$ & $<0.001$ & $<0.001$ \\
\hline \multicolumn{6}{|l|}{ Ethnic } \\
\hline Han & 7005 & $8.13 \pm 1.35$ & $0.87 \pm 0.62$ & $1.52 \pm 1.22$ & $5.68 \pm 1.92$ \\
\hline Uyghur & 3303 & $6.06 \pm 1.22^{\mathrm{a}}$ & $0.71 \pm 0.31$ & $1.21 \pm 1.03^{\mathrm{a}}$ & $5.28 \pm 3.41^{\mathrm{a}}$ \\
\hline Kazak & 359 & $5.96 \pm 1.42^{\mathrm{a}, \mathrm{c}}$ & $0.66 \pm 0.42$ & $1.43 \pm 1.13^{b, c}$ & $4.07 \pm 2.73^{\mathrm{a}, \mathrm{b}, \mathrm{c}}$ \\
\hline Other minorities & 1224 & $7.52 \pm 1.06$ & $0.81 \pm 0.34$ & $1.23 \pm 1.02$ & $5.42 \pm 3.12$ \\
\hline$F$ & & 2087.29 & 81.63 & 64.73 & 26.77 \\
\hline$p$-value & & $<0.001$ & $<0.001$ & $<0.001$ & $<0.001$ \\
\hline \multicolumn{6}{|l|}{ Occupation } \\
\hline Knowledge workers & 4197 & $8.71 \pm 1.61$ & $0.82 \pm 0.70$ & $1.41 \pm 1.08$ & $6.23 \pm 3.20$ \\
\hline Manual workers & 7694 & $6.06 \pm 1.22$ & $0.92 \pm 0.35$ & $1.62 \pm 1.13$ & $5.11 \pm 2.69$ \\
\hline$t$ & & 10.12 & 9.37 & 9.86 & 19.36 \\
\hline$p$-value & & $<0.001$ & $<0.001$ & $<0.001$ & $<0.001$ \\
\hline
\end{tabular}


Table 3. Cont.

\begin{tabular}{|c|c|c|c|c|c|}
\hline & $n$ & Self-Esteem & Anxiety & Depression & Total Score \\
\hline \multicolumn{6}{|l|}{ Working years } \\
\hline$<5$ & 2164 & $3.15 \pm 0.31$ & $0.86 \pm 0.32$ & $1.43 \pm 1.23$ & $5.42 \pm 3.20$ \\
\hline $5-15$ & 3353 & $5.21 \pm 1.13^{d}$ & $0.72 \pm 0.21$ & $1.21 \pm 1.03^{\mathrm{d}}$ & $4.21 \pm 2.51$ \\
\hline$\geq 15$ & 6374 & $5.96 \pm 1.42^{d}$ & $0.53 \pm 0.32 \mathrm{~d}, \mathrm{e}$ & $1.13 \pm 1.02^{\mathrm{d}}$ & $3.76 \pm 2.63^{d}$ \\
\hline \multirow{2}{*}{\multicolumn{2}{|c|}{$\begin{array}{c}F \\
p \text {-value }\end{array}$}} & 4334.3 & 1181.72 & 64.5 & 390.73 \\
\hline & & $<0.001$ & $<0.001$ & $<0.001$ & $<0.001$ \\
\hline \multicolumn{6}{|l|}{ Marital } \\
\hline Unmarried & 5791 & $4.02 \pm 1.57$ & $0.66 \pm 0.42$ & $1.43 \pm 1.13$ & $3.26 \pm 2.52$ \\
\hline Married & 4994 & $5.31 \pm 1.21 \mathrm{~h}$ & $0.74 \pm 0.31^{\mathrm{h}}$ & $1.33 \pm 1.01^{\mathrm{h}}$ & $3.58 \pm 2.64 \mathrm{~h}$ \\
\hline Divorce, death of a spouse & 868 & $3.21 \pm 1.02^{\mathrm{f}, \mathrm{g}, \mathrm{h}}$ & $0.69 \pm 0.11$ & $1.17 \pm 0.97^{\mathrm{f}, \mathrm{g}, \mathrm{h}}$ & $4.07 \pm 3.07^{\mathrm{f}, \mathrm{h}}$ \\
\hline Remarriage & 238 & $4.81 \pm 1.84^{\mathrm{f}}$ & $0.86 \pm 0.26^{\mathrm{f}, \mathrm{h}}$ & $1.53 \pm 0.68$ & $3.96 \pm 2.45^{\mathrm{f}}$ \\
\hline \multirow{2}{*}{\multicolumn{2}{|c|}{$\begin{array}{c}F \\
p \text {-value }\end{array}$}} & 933.54 & 59.87 & 20.38 & 74.56 \\
\hline & & $<0.001$ & $<0.001$ & $<0.001$ & $<0.001$ \\
\hline \multicolumn{6}{|l|}{ Drinking } \\
\hline Yes & 4007 & $5.02 \pm 1.57$ & $0.87 \pm 0.67$ & $1.53 \pm 1.13$ & $4.56 \pm 2.16$ \\
\hline No & 7884 & $5.87 \pm 1.61$ & $0.53 \pm 0.50$ & $1.66 \pm 1.32$ & $4.50 \pm 2.61$ \\
\hline \multirow{2}{*}{\multicolumn{2}{|c|}{$\begin{array}{c}t \\
p \text {-value }\end{array}$}} & 27.45 & 29.12 & 5.62 & 1.28 \\
\hline & & $<0.001$ & $<0.001$ & $<0.001$ & 0.21 \\
\hline \multicolumn{6}{|l|}{ Smoking } \\
\hline Yes & 2162 & $4.77 \pm 1.53$ & $0.52 \pm 0.32$ & $1.21 \pm 1.01$ & $4.07 \pm 3.07$ \\
\hline No & 9729 & $3.52 \pm 1.26$ & $0.61 \pm 0.41$ & $1.64 \pm 1.27$ & $4.88 \pm 3.31$ \\
\hline \multirow{2}{*}{\multicolumn{2}{|c|}{$\begin{array}{c}t \\
p \text {-value }\end{array}$}} & 36.71 & 10.57 & 15.72 & 10.53 \\
\hline & & $<0.001$ & $<0.001$ & $<0.001$ & $<0.001$ \\
\hline
\end{tabular}

Student-Newman-Keuls and least significant difference test results: ${ }^{\text {a }} p<0.003$ compared to Han ethnicity; ${ }^{\mathrm{b}} p<0.003$ compared to Uighur ethnicity; ${ }^{\mathrm{c}} p<0.003$ compared to other ethnic groups; ${ }^{\mathrm{d}} p<0.003$ compared to length of service $<5$ years; ${ }^{\mathrm{e}} p<0.003$ compared to length of service $5-15$ years; ${ }^{\text {f }} p<0.003$ compared to married people; ${ }^{\mathrm{g}} p<0.003$ compared to those who remarried; and ${ }^{\mathrm{h}} p<0.003$ compared to those who were unmarried.

\subsection{Risk Factors for the Poor Mental Health by Multivariable Logistic Regression Analysis}

To identify independent risk factors for the poor mental health, we conducted multivariable logistic regression including sex, ethnicity, occupation, working years, and marital status as independent variables ( $p=0.05$ boundary value) (Table 4). Female sex (OR $=1.139 ; 95 \%$ CI: $1.012-3.198$; $p<0.05)$ and knowledge work (OR $=1.697 ; 95 \%$ CI: 1.097-2.962; $p<0.05)$ were identified as independent risk factors. In contrast, Kazak ethnicity (OR $=0.465 ; 95 \% \mathrm{CI}$ : 0.466-0.937; $p<0.05)$, other minority status (OR $=0.806 ; 95 \% \mathrm{CI}: 0.205-0.987 ; p<0.05)$, and working years $\geq 15$ (OR $=0.832 ; 95 \% \mathrm{CI}$ : $0.532-0.932 ; p<0.05)$ were identified as protective factors.

Table 4. Logistic regression analysis of multiple factors influencing mental health.

\begin{tabular}{cccccccc}
\hline $\begin{array}{c}\text { Influence } \\
\text { Factor }\end{array}$ & $\begin{array}{c}\text { Reference } \\
\text { Group }\end{array}$ & Compare Group & $\boldsymbol{\beta}$ & S.E. & Wald & $p$-Value & OR (95\% CI) \\
\hline Sex & Male & Female & 0.130 & 0.026 & 24.721 & $<0.001$ & $1.139(1.012,3.198)$ \\
\hline \multirow{2}{*}{ Ethnic } & \multirow{2}{*}{ Han ethnic } & Uyghur & 0.836 & 0.224 & 1.646 & 0.292 & $2.307(0.276,2.482)$ \\
& & Kazak & -0.765 & 0.212 & 11.661 & $<0.001$ & $0.465(0.466,0.937)$ \\
& & Other minorities & -0.216 & 0.180 & 7.446 & 0.001 & $0.806(0.205,0.987)$ \\
\hline Working & \multirow{2}{*}{5} & $5-15$ & -0.410 & 0.592 & 0.481 & 0.488 & $0.664(0.208,2.117)$ \\
years & & $\geq 15$ & -0.195 & 0.207 & 0.978 & 0.012 & $0.832(0.532,0.932)$ \\
\hline Occupation & \multirow{2}{*}{ Manual workers } & Knowledge workers & 0.529 & 0.335 & 5.641 & 0.001 & $1.697(1.097,2.962)$ \\
\hline \multirow{2}{*}{$\begin{array}{c}\text { Marital } \\
\text { status }\end{array}$} & \multirow{2}{*}{ Unmarried } & Divorce, death of a spouse & 0.128 & 0.250 & 0.261 & 0.61 & $1.137(0.696,1.853)$ \\
& & Remarriage & -0.216 & 0.180 & 1.446 & 0.229 & $0.806(0.566,1.146)$ \\
\hline
\end{tabular}

Notes: backward stepwise (Wald) logistic regression analysis; OR = Odds ratios; $95 \% \mathrm{CI}=95 \%$ confidence intervals; the result of Hosmer-Lemeshow test is $p$-value $=0.251$.

The logistic regression model was statistically significant $\left(\chi^{2}=11.95, p<0.05\right)$, the model explained $48.5 \%$ of the variance in mental health status and correctly classified $81.69 \%$ of cases. This study suggests that the psychological health of the working population of Xinjiang is influenced strongly by 
sex, ethnicity, working years, and occupation. In general, females, members of the Han ethnic group, teachers, and healthcare workers demonstrated poorer mental health than males, ethnic minorities, and manual laborers.

\section{Discussion}

This is the first comprehensive study analyzing differences in mental health among ethnic and occupational groups in Xinjiang, China. Mental health levels were measured by the GHQ-20, with results demonstrating observable differences in regard to sex, ethnicity, occupation, and length of employment. Specifically, being female, as well as having an occupation in knowledge work, increased the risk of poor mental health. Protective factors included membership in the Kazak ethnic group or other ethnic minority, and $\geq 15$ years at the same job. The overall prevalence of poor mental health in our study was $23.8 \%$.

Total GHQ-20 scores were lower in the Uygur and Kazak minorities than in the majority Han ethnic group, possibly due to beliefs and religious activities that can lower the risk of mental health problems [47] and often give people hope and support when they are sick or in trouble [48]. Religious beliefs have also been shown to influence behavior and health in both simple and complex ways [49], and have been shown to have protective effects against depression and psychosis $[18,50]$. Additionally, greater religiousness has been shown to be mildly associated with fewer depression symptoms [50]. The mental health of manual workers was better than that of knowledge workers due to the high incidence of poor mental health in occupations such as civil servants, teachers, and healthcare workers. Long working hours and a heavy workload are known to be intrinsic properties of healthcare workers, and they are faced with many other psychosocial work hazards including high psychological demands, low support, and increasing violence in the workplace [51]; all these factors possibly enhance the risk of mental health [52]. In recent years, increasing violence in the workplace and poor working environments also increased the chronic stress levels of civil servants [52] and healthcare workers [53,54]. Additionally, teachers, whose profession entails intimate contact with children and young people [55], are known to be at an increased risk of mental health problems [56] due to the heightened job demands and work stress [57], including, for example, difficulties associated with managing classes effectively and developing supportive relationships with students [58].

The overall levels of anxiety and depression were higher in working females than males, consistent with a previous study examining occupational mental health [59]. Greater depression and anxiety in working females may arise from the dual roles played by working women, given that many may not only bear the pressures of work but also expectations of achieving a balance with family life. Indeed, such conflicts have been associated with greater susceptibility to depression in working women [60]. In contrast, workers engaged in the same occupation for a longer period reported better mental health, possibly because such workers can use their abundant work and social experience to deal with work and life pressures, thereby sustaining good mental health [61]. Married people also had lower risk of poor mental health for both sexes compared to people who divorced or widowed, which is consistent with other studies $[62,63]$. The majority of women who experienced divorce or who were widowed were more likely to suffer from reduced sexual frequency, depression, and anxiety [64]. The anxiety level of frequent drinkers was higher but the depression level was lower, consistent with a previous study [62]. In our study, the physical and mental health of smokers was better than non-smokers, which is in contrast to other studies [12,13]. This is possibly related to the reliability of our study (Cronbach's alpha was 0.862 ) and influenced by other factors that were not noticed and should have been considered, such as social support, and economic and education level. While the sample size of this study was relatively large, a number of limitations should be considered. First, all participants completed the questionnaire independently, so the results may be corrupted by reporting and information bias, and the reliability of the GHQ-20 in our study was not high. Second, it is not known if these results can be extrapolated to other regions of China or other countries. Third, demographic and social factors not considered in this study, such as working 
conditions, social support, economic level, and education, may have influenced the mental health of the different ethnicities, and occupational groups. Forth, this cross-sectional study could not assess possible causes for these differences, such as the factors leading to higher levels of depression and anxiety in knowledge workers. Follow-up research should concentrate on the mechanisms by which ethnicity and occupation influence mental health. Nonetheless, we have identified occupational subgroups particularly prone to poor mental health (e.g., inexperienced female teachers) that require targeted programs and social support.

\section{Conclusions}

In conclusion, this study found statistically significant differences in the mental health levels among different ethnic and occupational subgroups in Xinjiang province, China. The overall mental health status of Uyghur and Kazak ethnic groups, independent of occupation, tended to be better than that of the Han ethnic group. Manual workers reported better mental health status than knowledge workers, primarily due to the poor mental health of civil servants, healthcare workers, and teachers.

Acknowledgments: The study was funded by the National Natural Science Foundation of China (Grant Numbers: 81260425). The authors thank all participants and investigators.

Author Contributions: Ailing Fu and Jiwen Liu designed the study and wrote the paper. Bo Liu collected and analyzed the data. Yu Jiang, Junling Zhao, and Guanghui Zhang performed the study and conducted the quality control. All authors discussed and approval the manuscript.

Conflicts of Interest: The authors declare no conflicts of interest.

\section{References}

1. Gallagher, M.B.; Muldoon, O.T.; Pettigrew, J. An integrative review of social and occupational factors influencing health and wellbeing. Front. Psychol. 2015, 6, 1281. [CrossRef] [PubMed]

2. Rutz, W. A need to rethink social psychiatry in Europe. Lancet 2004, 363, 1652. [CrossRef]

3. Conway, M.; O'Connor, D. Social Media, Big Data, and Mental health: Current Advances and Ethical Implications. Curr. Opin. Psychol. 2016, 9, 77-82. [CrossRef] [PubMed]

4. Whiteford, H.A.; Degenhardt, L.; Rehm, J.; Baxter, A.J.; Ferrari, A.J.; Erskine, H.E.; Charlson, F.J.; Norman, R.E.; Flaxman, A.D.; Johns, N.; et al. Global burden of disease attributable to mental and substance use disorders: findings from the global burden of disease study 2010. Lancet 2013, 382, 1575-1586. [CrossRef]

5. Simon, G.; Peter, B.; Jo, R. Better care for depression in the workplace: Integrating occupational and mental health services. Br. J. Psychiatry 2012, 200, 442-443.

6. Saxena, S.; Funk, M.K.; Chisholm, D. Comprehensive Mental Health Action Plan 2013-2020. East Mediterr. Health J. 2015, 21, 461-463. [PubMed]

7. Skapinakis, P.; Bellos, S.; Koupidis, S.; Grammatikopoulos, I.; Theodorakis, P.N.; Mavreas, V. Prevalence and sociodemographic associations of common mental disorders in a nationally representative sample of the general population of Greece. BMC Psychiatry 2013, 13, 163. [CrossRef] [PubMed]

8. Nunes, M.A.; Pinheiro, A.P.; Bessel, M.; Brunoni, A.R.; Kemp, A.H.; Benseñor, I.M.; Chor, D.; Barreto, S.; Schmidt, M.I. Common mental disorders and Sociodemographic characteristics: Baseline findings of the Brazilian Longitudinal the Brazilian Longitudinal Study of Adult Health (ELSA-Brasil). Rev. Bras. Psiquiatr. 2016, 38, 91-97. [CrossRef] [PubMed]

9. Room, R.; Gureje, O.; Jernigan, D.; Mäkelä, K.; Marshall, M.; Carlini-Marlatt, B. Alcohol in a Changing World; Cambridge University Press: Cambridge, UK, 2003.

10. Gilder, D.A.; Lau, P.; Gross, A.; Ehlers, C.L. A co-morbidity of alcohol dependence with other psychiatric disorders in young adult Mexican Americans. J. Addict. Dis. 2007, 26, 31-40. [CrossRef] [PubMed]

11. Rincon-Hoyos, H.G.; Castillo, A.; Prada, S.I. Alcohol use disorders and psychiatric diseases in Colombia. Colomb. Med. (Cali) 2016, 47, 31-37. [PubMed]

12. Mario, G.B.; María, S.G.; Enrique, G.G.; Maira, B.R.; Miguel, A.M.G. Smoking Status, Changes in Smoking Status and Health-Related Quality of Life: Findings from the SUN ("Seguimiento Universidad de Navarra") Cohort. Int. J. Environ. Res. Public Health 2009, 6, 310-320. 
13. Amedeo, M.; Francesco, S.B.; Wanda, K.C.; Francesco, S.; Marta, F.; Roberto, V.; Roberto, D.C.; Massimo, B. Smoking behaviour and mental health disorders-Mutual influences and implications for therapy. Int. J. Environ. Res. Public Health 2013, 10, 4790-4811.

14. Fryers, T.; Melzer, D.; Jenkins, R. Social inequalities and the common mental disorders: A systematic review of the evidence. Soc. Psychiatry Psychiatr. Epidemiol. 2003, 38, 229-237. [CrossRef] [PubMed]

15. Nieuwenhuijsen, K.; Schene, A.H.; Stronks, K.; Snijder, M.B.; Frings-Dresen, M.H.; Sluiter, J.K. Do unfavourable working conditions explain mental health inequalities between ethnic groups? Cross-sectional data of the HELIUS study. BMC Public Health 2015, 15, 805. [CrossRef] [PubMed]

16. Gajwani, R.; Parsons, H.; Birchwood, M.; Singh, S.P. Ethnicity and detention: Are Black and minority ethnic (BME) groups disproportionately detained under the Mental Health Act 2007? Soc. Psychiatry Psychiatr. Epidemiol. 2016, 51, 703-711. [CrossRef] [PubMed]

17. Corrigall, R.; Bhugra, D. The role of ethnicity and diagnosis in rates of adolescent psychiatric admission and compulsory detention: A longitudinal case-note study. J. R. Soc. Med. 2013, 106, 190-195. [CrossRef] [PubMed]

18. Dein, S.; Bhui, K.S. At the crossroads of anthropology and epidemiology: Current research in cultural psychiatry in the UK. Transcult. Psychiatry 2013, 50, 769-791. [CrossRef] [PubMed]

19. Ghaddar, A.; Mateo, I.; Sanchez, P. Occupational tress and mental health among correctional officers: A cross-sectional study. J. Occup. Health 2008, 50, 92-98. [CrossRef] [PubMed]

20. Cheng, W.J.; Cheng, Y. Minor mental disorders in Taiwanese healthcare workers and the associations with psychosocial work conditions. J. Formos. Med. Assoc. 2016, 5, 1-6. [CrossRef] [PubMed]

21. Stansfeld, S.; Candy, B.P. Sychosocial work environment and mental health-A meta-analytic review. Scand. J. Work Environ. Health 2006, 32, 443-462. [CrossRef] [PubMed]

22. Kobayashi, Y.; Hirose, T.; Tada, Y.; Tsutsumi, A.; Kawakami, N. Relationship between two job stress models and coronary risk factors among Japanese part-time female employees of a retail company. J. Occup. Health 2005, 47, 201-210. [CrossRef] [PubMed]

23. Lopes, C.S.; Moraes, C.L.; Junger, W.L.; Werneck, G.L.; Ponce de Leon, C.; Faerstein, E. Direct and indirect exposure to volence and psychologicaldistress among civil servants in Rio de Janeiro, Brazil: A prospective cohort study. BMC Psychiatry 2015, 15, 109. [CrossRef] [PubMed]

24. Soeda, S.; Hayashi, T.; Sugawara, Y.; Takano, T.; Terao, T.; Nakamura, J. A comparison of white-collar jobs in regard to mental health consultation rates in a health care center operated by a Japanese company. Ind. Health 2003, 41, 117-119. [CrossRef] [PubMed]

25. Tatsuse, T.; Sekine, M. Job dissatisfaction as a contributor to stress-related mental health problems among Japanese civil servants. Ind. Health 2013, 51, 307-318. [CrossRef] [PubMed]

26. Kutcher, S.; Wei, Y.; Gilberds, H.; Ubuguyu, O.; Njau, T.; Brown, A.; Sabuni, N.; Magimba, A.; Perkins, K. A school mental health literacy curriculum resource training approach: Effects on Tanzanian teachers' mental health knowledge, stigma and help-seeking efficacy. Int. J. Ment. Health Syst. 2016, 10, 50. [CrossRef] [PubMed]

27. Silva-Junior, J.S. Preventing occupational stress in healthcare workers. Sao Paulo Med. J. 2016, 134, 92. [PubMed]

28. Cohen, J.S.; Patten, S. Well-being in residency training: A survey examining esident physician satisfaction both within and outside of residency training and mental health in Alberta. BMC Med. Educ. 2005, 5, 21. [CrossRef] [PubMed]

29. Perkins, D.; Fuller, J.; Kelly, B.J.; Lewin, T.J.; Fitzgerald, M.; Coleman, C.; Inder, K.J.; Allan, J.; Arya, D.; Roberts, R.; et al. Factors associated with reported service use for mental health problems by residents of rural and remote communities: Cross-sectional findings from a baseline survey. BMC Health Serv. Res. 2013, 13, 157. [CrossRef] [PubMed]

30. Adrianna, W.Z.; Kearney, C.A. Depression and symptoms of posttraumatic stress disorder in Maltreated Adolescents. J. Child Adolesc. Trauma 2015, 8, 13-20.

31. Kroon, B.; Van Voorde, K.; Van Veldhoven, M. Cross-level effects of high-performance work practices on burnout: Two counteracting mediating mechanisms compared. Pers. Rev. 2009, 38, 509-525. [CrossRef]

32. Ludwig, A.B.; Burton, W.; Weingarten, J.; Milan, F.; Myers, D.C.; Kligler, B. Depression and stress amongst undergraduate medical students. BMC Med. Educ. 2015, 15, 34-36. [CrossRef] [PubMed] 
33. Saleh, K.J.; Quick, J.C.; Conaway, M.; Sime, W.E.; Martin, W.; Hurwitz, S.; Einhorn, T.A. The prevalence and severity of burnout among academic qrthopaedic departmental leaders. J. Bone Jt. Surg. Am. 2007, 89, 896-903.

34. Rivara, F.P.; McCarty, C.A.; Shandro, J.; Wang, J.; Zatzick, D. Parental injury and psychological health of children. Pediatrics 2014, 134, 88-97. [CrossRef] [PubMed]

35. Paul, R.M.; Rochelle, C.; Helen, L.; Lina, R. The training crisis in health psychology in Australia. Aust. Psychol. 2014, 49, 86-95.

36. Conor, F.; Mike, M. Burnout in Irish teachers: Investigating the role of individual differences, work environment and coping factors. Teach. Teach. Educ. 2015, 50, 46-50.

37. Wang, S.S.; Liu, Y.; Wang, L.L. Nurse Burnout: Personal and environmental factors as predictors. Int. J. Nurs. Pract. 2015, 21, 78-86. [CrossRef] [PubMed]

38. Gärtner, F.R.; Ketelaar, S.M.; Smeets, O.; Bolier, L.; Fischer, E.; van, F.J.; Nieuwenhuijsen, K.; Sluiter, J.K. The Mental Vitality @ Work study: Design of a randomized controlled trial on the effect of a workers' health surveillance mental module for nurses and allied health professionals. BMC Public Health 2011, 11, 290. [CrossRef] [PubMed]

39. Sreeramareddy, C.T.; Shankar, P.R.; Binu, V.S.; Mukhopadhyay, C.; Ray, B.; Menezes, R.G. Psychological morbidity, sources of stress and coping strategies among undergraduate medical students of Nepal. BMC Med. Educ. 2007, 7, 26. [CrossRef] [PubMed]

40. Stansfeld, S.A.; Pike, C.; McManus, S.; Harris, J.; Bebbington, P.; Brugha, T.; Hassiotis, A.; Jenkins, R.; Meltzer, H.; Moran, P.; et al. Occupations, work characteristics and common mental disorder. Psychol. Med. 2013, 43, 961-973. [CrossRef] [PubMed]

41. Li, H.; Mei, J.R. Assessing psychological well-being of college students: Psychometric properties of the GHQ-20. Psychol. Dev. Educ. 2002, 18, 75-79. (In Chinese)

42. Mari, J.J.; Williams, P. A comparison of the validity of two psychiatrics screening questionnaires (GHQ-12 and SRQ-20) in Brazil, using relative operating characteristic (ROC) analysis. Psychol. Med. 1985, 15, 651-659. [CrossRef] [PubMed]

43. Cheng, T.A.; Wu, J.T.; Chong, M.Y.; Williams, P. Internal consistency and factor structure of the Chinese Health Questionnaire. Acta Psychiatr. Scand. 1990, 82, 304-308. [CrossRef] [PubMed]

44. Liu, J.J.; Zhao, J.L.; Wang, L.; Pan, K.; Liu, J.W. Psychological health and occupational stress among occupation populations in Xinjiang. Chin. J. Public Health 2015, 31, 439-441. (In Chinese)

45. Wik, H.S.; Jacobsen, A.F.; Sandvik, L.; Sandset, P.M. Long-term impact of pregnancy-related venous thrombosis on quality-of-life, general health and functioning: Results of a cross-sectional, case-control study. BMJ Open 2012, 2, e002048. [CrossRef] [PubMed]

46. Linna, M.S.; Kaprio, J.; Raevuori, A.; Sihvola, E.; Keski-Rahkonen, A.; Rissanen, A. Body mass index and subjective well-being in young adults: A twin population study. BMC Public Health 2013, 13, 231. [CrossRef] [PubMed]

47. Faria, N.M.; Fassa, A.G.; Meucci, R.D.; Fiori, N.S.; Miranda, V.I. Occupational exposure to pesticides, nicotine and minor psychiatric disorders among tobacco farmers in southern Brazil. Neurotoxicology 2014, 45, 347-354. [CrossRef] [PubMed]

48. Lilja, A.; DeMarinis, V.; Lehti, A.; Forssén, A. Experiences and explanations of mental ill health in a group of devout Christians from the ethnic majority population in secular Sweden: A qualitative study. BMJ Open 2016, 6, e011647. [CrossRef] [PubMed]

49. Leavey, G.; Loewenthal, K.; King, M.J. Locating the social origins of mental illness: The explanatory models of mental illness among clergy from different ethnic and faith backgrounds. J. Relig. Health 2016, 55, 1607-1622. [CrossRef] [PubMed]

50. Smith, T.B.; McCullough, M.E.; Poll, J. Religiousness and depression: Evidence for a main effect and the moderating influence of stressful life events. Psychol. Bull. 2003, 129, 614-636. [CrossRef] [PubMed]

51. Pisljar, T.; van der Lippe, T.; den Dulk, L. Health among hospital employees in Europe: A cross-national study of the impact of work stress and work control. Soc. Sci. Med. 2011, 72, 899-906. [CrossRef] [PubMed]

52. Wall, T.D.; Bolden, R.I.; Borrill, C.S.; Carter, A.J.; Golya, D.A.; Hardy, G.E.; Haynes, C.E.; Rick, J.E.; Shapiro, D.A.; West, M.A. Minor psychiatric disorder in NHS trust staff: Occupational and gender differences. Br. J. Psychiatry 1997, 171, 519-523. [CrossRef] [PubMed] 
53. Lacovides, A.; Fountoulakis, K.N.; Kaprinis, S.; Kaprinis, G. The relationship between job stress, burnout and clinical depression. J. Affect. Disord. 2003, 75, 209-221. [CrossRef]

54. Wallace, J.E.; Lemaire, J.B.; Ghali, W.A. Physician wellness: A missing quality indicator. Lancet 2009, 374, 1714-1721. [CrossRef]

55. Kidger, J.; Evans, R.; Tilling, K.; Hollingworth, W.; Campbell, R.; Ford, T.; Murphy, S.; Araya, R.; Morris, R.; Kadir, B.; et al. Protocol for a cluster randomised controlled trial of an intervention to improve the mental health support and training available to secondary school teachers-The WISE (Wellbeing in Secondary Education) study. BMC Public Health 2016, 16, 1089. [CrossRef] [PubMed]

56. Stansfeld, S.A.; Rasul, F.R.; Head, J.; Singleton, N. Occupation and mental health in a national UK survey. Soc. Psychiatr. Psychiatr. Epidemiol. 2011, 46, 101-110. [CrossRef] [PubMed]

57. Melchior, M.; Caspi, A.; Milne, B.J.; Danese, A.; Poulton, R.; Moffitt, T.E. Work Stress precipitates depression and anxiety in young, working women and men. Psychol. Med. 2007, 37, 1119-1129. [CrossRef] [PubMed]

58. Jennings, P.A.; Frank, J.L.; Snowberg, K.E.; Coccia, M.A.; Greenberg, M.T. Improving classroom learning environments by Cultivating Awareness and Resilience in Education (CARE): Results of a randomized controlled trial. Sch. Psychol. Q. 2013, 28, 374-390. [CrossRef] [PubMed]

59. Marchand, A.; Blanc, M.E.; Durand, P. Gender, age, occupation, economic sector and mental health in the workplace: The results of the study SALVEO. Can. J. Public Health 2015, 106, e223-e229. [PubMed]

60. Ahola, K.; Honkonen, T.; Virtanen, M.; Aromaa, A.; Lönnqvist, J. Burnout in relation to age in the adult working Population. J. Occup. Health 2008, 50, 362-365. [CrossRef] [PubMed]

61. Soares, J.; Grossi, G.; Sundin, O. Burnout among women: Associations with demographic/social-economic, work, life-style and health factors. Arch. Womens Men Health 2007, 10, 61-71. [CrossRef] [PubMed]

62. Beseler, C.L.; Stallones, L. A cohort study of pesticide poisoning and epression in Colorado farm residents. Ann. Epidemiol. 2008, 18, 768-774. [CrossRef] [PubMed]

63. Blumel, J.E.; Chedraui, P.; Baron, G.; Belzares, E.; Bencosme, A.; Calle, A.; Espinoza, M.T.; Flores, D.; Izaguirre, H.; Leon, L.P.; et al. Sexualdysfunction in middle-aged women: A multicenter Latin American study using the Female Sexual Function Index. Menopause 2009, 16, 1139-1148. [CrossRef] [PubMed]

64. Nazarpour, S.; Simbar, M.; Tehrani, F.R. Factors affecting sexual function in menopause: A review article. Taiwan. J. Obstet. Gynecol. 2016, 55, 480-487. [CrossRef] [PubMed]

(C) 2017 by the authors; licensee MDPI, Basel, Switzerland. This article is an open access article distributed under the terms and conditions of the Creative Commons Attribution (CC-BY) license (http://creativecommons.org/licenses/by/4.0/). 